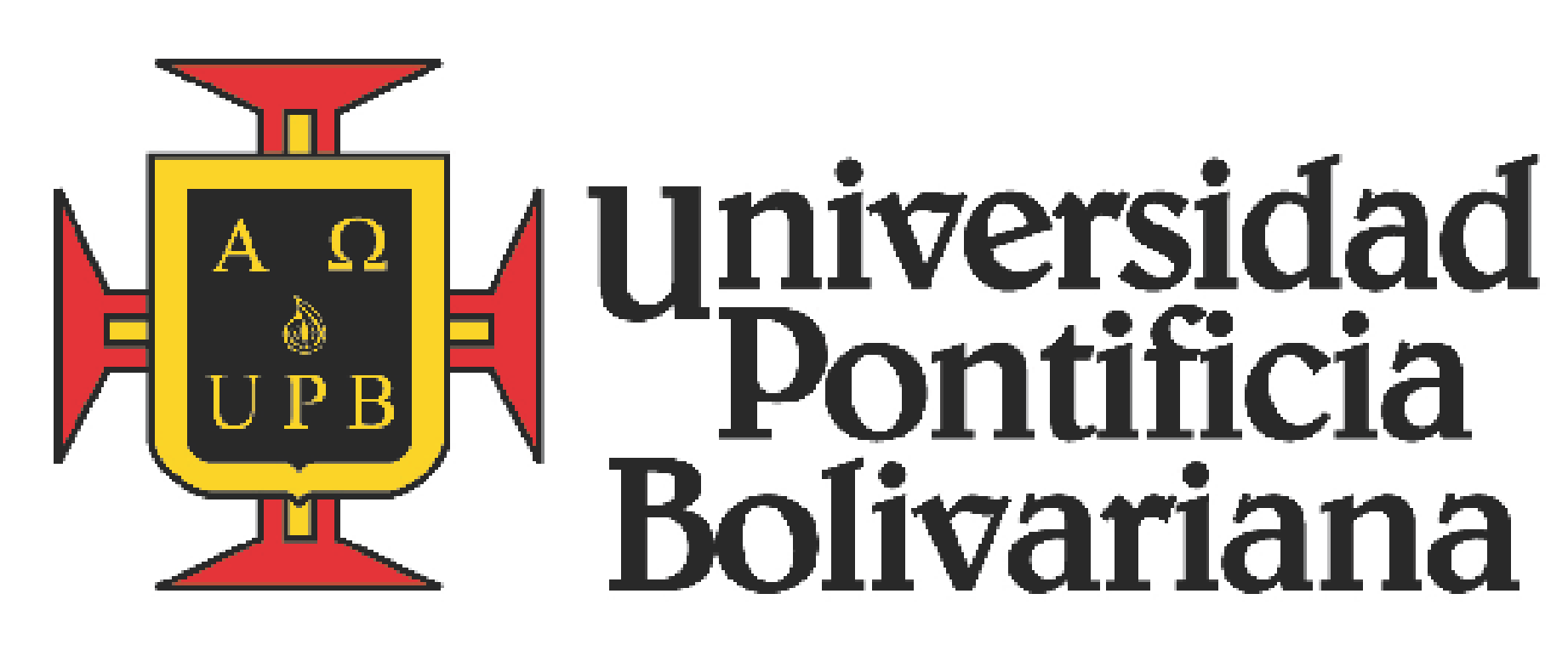

\title{
Clinical and epidemiological profile of patients with hyperthyroidism and hypothyroidism that receive endocrinological services from a medical institution in Medellín (Colombia) between 2013 and 2015
}

\section{| Introduction}

Endocrine Illnesses have high prevalence on a global level due to multiple etiologies that can lead alterations to this system.

Thyroid disorders

$\mathrm{T} 3$ and
Decreased T3
and T4 levels

\section{General objective}

Determine the epidemiological profile of hyperthyroid and hypothyroid patients that receive endocrinological services from a medical institution in Medellin (Colombia) between 2013 and 2015.

\section{Metodology}

- Study Type: A descriptive, retrospective study was conducted and included the clinical records of patients diagnosed with hyperthyroidism or hypothyroidism. A univariate analysis was applied using descriptive statistics by means of absolute frequencies and proportions in the SPSS software, version 19.0

- Population: Clinical files of patients with hyper/hypothyroidism who were in treatment for this pathology.

- Data collection: Was done using a form designed by the research group in which all the necessary data for the description of the clinical and epidemiological profile was included

- Data analysis: Univariate analysis was performed with descriptive statiscs through absolute frequencies and proportions in SPSS $®$ v19.0 program.

- Ethics: The research was approved by the Ethics Committee of the univeersity, the confidentiality of the data contained in clinical records was kept and it was classified as an investigation without risk according to the 008430 Colombian Ministry of Health Resolution of 1993

\section{Results}

In the study of 159 patients, 131 had hypothyroidism and 18 hyperthyroidism, the middle age was $56.7 \pm 17.8$ years and $55.6 \pm 15.1$ years, respectively.

Table 1. Main causes of hypo/hyperthyroidism in study population

\begin{tabular}{|lcc|}
\hline \multicolumn{1}{|c}{ Causes } & Hypothyroidism & Hyperthyroidism \\
\hline Hashimoto disease & $5.3 \%$ & $0.0 \%$ \\
\hline Graves disease & $0.0 \%$ & $33.3 \%$ \\
\hline Post surgical & $11.5 \%$ & $0.0 \%$ \\
\hline Panhypopituitarism & $0.8 \%$ & $5.6 \%$ \\
\hline Thyrotoxicosis & $0.0 \%$ & $22.2 \%$ \\
\hline Multinodular goiter & $3.1 \%$ & $16.7 \%$ \\
\hline Thyroid nodule & $0.8 \%$ & $5.6 \%$ \\
\hline
\end{tabular}

The main signs and symptoms of the studied patients can be apreciated in Table 2. The goiter was common in $14.5 \%$ and $38.9 \%$ of hypo and hyperthyroidism.

Table 2. Common signs and symptoms

\begin{tabular}{|lcc|}
\hline $\begin{array}{c}\text { Signs and } \\
\text { symptoms }\end{array}$ & Hypothyroidism & Hyperthyroidism \\
\hline Headache & $26.0 \%$ & $33.3 \%$ \\
\hline Fatigue & $26.7 \%$ & $27.8 \%$ \\
\hline Tachycardia & $2.3 \%$ & $27.8 \%$ \\
\hline Exophthalmos & $0.8 \%$ & $27.8 \%$ \\
\hline Palpitations & $4.6 \%$ & $22.2 \%$ \\
\hline Weight loss & $3.1 \%$ & $22.2 \%$ \\
\hline Anxiety & $12.2 \%$ & $11.1 \%$ \\
\hline Weight gain & $3.8 \%$ & $11.1 \%$ \\
\hline Hair loss & $4.6 \%$ & $5.6 \%$ \\
\hline
\end{tabular}

In the Figure 1 can be observed the principal treatments in each pathology, with levothyroxine and methimazole as the main drugs in hypothyroidism and hyperthyroidism respectively.

Figure 1. Main treatments in hypo/hyperthyroidism

90

80

70

50

40

30

20
10

0

Co

\section{Conclusion}

The results align with what is described in the literature of both pathologies, being more common in women with primary gland disfunction. In relation to classic symptoms of the disease such as fatigue and adynamia, neither were the most relevant in this study.

\section{Conflicts of interest}

The authors declare no conflicts of interest.

\section{Bibliography}

Ling Y, Jiang J, Gui M, Liu L, Aleteng Q, Wu B, et al. Thyroid Function, Prevalent Coronary Heart Disease, and Severity of Coronary Atherosclerosis in Patients Undergoing Coronary Angiography. Int J Endocrinol Metab. 2015; 1-9.

Yang MH, Yang FY, Lee DD. Thyroid Disease as a Risk Factor for Cerebrovascular Disease. J Stroke Cerebrovasc Dis. 2015;24(5):912-20.

Delitala AP, Terracciano A, Fiorillo E, Orrú V, Schelssinger D, Cucca F. Depressive symptoms, thyroid hormone and autoimmunity in a population-based cohort from Sardinia Journal of Affective Disorders. 2016; 191; 82-87. 